\title{
Early risk of stroke after a transient ischemic attack in patients with internal carotid artery disease
}

\author{
Michael Eliasziw, James Kennedy, Michael D. Hill, Alastair M. Buchan, Henry J.M. Barnett, \\ for the North American Symptomatic Carotid Endarterectomy Trial (NASCET) Group
}

ß See related articles pages 1099, 1113, 1123 and 1134

Abstract

Background: Transient ischemic attacks (TIAs) often herald a stroke, but little is known about the acute natural history of TIAs. Our objective was to quantify the early risk of stroke after a TIA in patients with internal carotid artery disease.

Methods: Using patient data from the medical arm of the North American Symptomatic Carotid Endarterectomy Trial, we calculated the risk of ipsilateral stroke in the territory of the symptomatic internal carotid artery within 2 and 90 days after a first-recorded hemispheric TIA. We also studied similar outcomes among patients in the trial who had a first-recorded completed hemispheric stroke.

Results: For patients with a first-recorded hemispheric TIA ( $n=$ 603), the 90-day risk of ipsilateral stroke was $20.1 \%$ (95\% confidence interval $[\mathrm{Cl}] 17.0 \%-23.2 \%$ ), higher than the $2.3 \%$ risk (95\% Cl $1.0 \%-3.6 \%)$ for patients with a hemispheric stroke $(n=526)$. The 2 -day risks were $5.5 \%$ and $0.0 \%$, respectively. Patients with more severe stenosis of the internal carotid artery (> 70\%) appeared to be at no greater risk of stroke than patients with lesser degrees of stenosis (adjusted hazard ratio 1.1, 95\% $\mathrm{Cl}$ 0.7-1.7). Infarct on brain imaging (adjusted hazard ratio 2.1, 95\% Cl 1.5-3.0) and the presence of intracranial major-artery disease (adjusted hazard ratio $1.9,95 \% \mathrm{Cl} 1.3-2.7$ ) doubled the early risk of stroke in patients with a hemispheric TIA.

Interpretation: Patients who had a hemispheric TIA related to internal carotid artery disease had a high risk of stroke in the first few days after the TIA. Early risk of stroke was not affected by the degree of internal carotid artery stenosis.

CMAJ 2004;170(7):1105-9

A transient ischemic attack (TIA) is a common neurological condition that is seen by all physician groups including family and emergency physicians, internists, vascular surgeons, and neurologists. In Canada, half a million adults aged 18 and over have been diagnosed with a TIA. ${ }^{1}$ Presenting symptoms vary depending on which arterial supply is compromised, but they commonly consist of a brief episode of weakness, numbness, loss of vision or speech difficulty with complete recovery.

Atherosclerotic disease of the carotid arteries outside the cranial cavity has long been recognized as the most common source of emboli that then travel to the brain causing stroke..$^{2-4}$ TIAs are often early warning signs of atheroscle- rotic disease. About $10 \%$ of patients with a TIA presenting to California emergency departments returned to the emergency department with a stroke within 90 days. $^{5}$ In half of the patients, the stroke occurred within the first 48 hours after the TIA. Similar 90-day results have been observed in earlier community-based studies. ${ }^{6-8}$ However, these studies all included some patients who had emboli from heart lesions or arrhythmias and some patients who had small-vessel disease as a cause of their TIA.

Although several large stroke-prevention trials among patients with TIAs ${ }^{9-18}$ have presented some data on the risk of stroke from pre-existing atherosclerotic disease of the carotid arteries, they are limited because enrolment in the trials was delayed by 1 or more months after the TIA occurred. Small case series ${ }^{19,20}$ have examined the relation between carotid artery disease and TIA, but without assessment of stroke outcome. Thus, the influence of atherosclerotic disease in the carotid artery on early stroke occurrence among people presenting with a TIA has not been assessed in any large study. ${ }^{21}$

Using patients from the medical arm of the North American Symptomatic Carotid Endarterectomy Trial (NASCET), we describe the early risk of stroke in a large number of patients with a TIA in whom internal carotid artery disease was the only presumed cause.

\section{Methods}

The NASCET was a randomized, multicentre clinical trial designed to determine the efficacy of carotid endarterectomy among patients with ischemic symptoms associated with internal carotid artery disease. Patients were enrolled in the trial if they had had a retinal or hemispheric TIA or a completed retinal or hemispheric ischemic stroke within 180 days before randomization. A retinal TIA was defined as a partial or complete visual field loss in 1 eye of ischemic origin lasting less than 24 hours. A hemispheric TIA was defined as a focal cerebral dysfunction of ischemic origin lasting less than 24 hours. A stroke was defined as a neurological dysfunction of ischemic origin with deficits persisting longer than 24 hours. The trial protocol was approved by the institutional review board at each participating centre, and written informed consent was obtained from each patient.

From December 1987 to December 1996, patients were randomly assigned to best contemporary medical care $(n=1449)$ or best contemporary medical care plus carotid endarterectomy $(n=$ 
1436) and followed to the end of December 1997. Details of the methods $^{22}$ and final results ${ }^{23}$ have been published. Patients were not eligible if they had a probable cardiac source of embolism or a serious disease likely to cause death within 5 years. Patients with disabling stroke before randomization were also excluded.

All patients underwent a detailed medical examination at baseline, including echocardiography and chest radiography. CT or MRI scanning of the brain was performed before randomization to determine the presence of infarcts and to rule out structural lesions that could have caused stroke-like symptoms. The degree of internal carotid artery stenosis was measured from a conventional carotid angiogram using strict criteria. ${ }^{24}$ Patient follow-up consisted of clinical examinations at 30 days, at 3, 6, 9 and 12 months, and every 4 months thereafter.

Data collection for this trial included a face-to-face patient interview in which all ischemic events occurring within 180 days before randomization were recorded. Clinical details of ischemic events, including type, duration and number, were collected as part of the trial protocol by the participating stroke neurologist. A written narrative of the patient's medical history was included in the case report form. Following data collection, all events were scrutinized by the trial's medical data managers and stroke fellows and were reconciled with the written narrative.

The territory and type of stroke (ischemic or hemorrhagic) occurring during follow-up were centrally reviewed. The presumed cause of each ischemic stroke was designated as large-artery, lacunar or cardioembolic. Definition of lacunar strokes was based on conformity with the 5 classic lacunar syndromes, with or without deep lesions no more than $1 \mathrm{~cm}$ in diameter visible by CT brain imaging. ${ }^{25}$ Cardioembolic strokes were defined using a combination of clinical and echocardiographic criteria. ${ }^{26}$ Ischemic strokes that were not lacunar or cardioembolic were classified as large-artery strokes.
This study is distinct from previous reports from the NASCET in that we chose to measure time and count events from the date of the first-recorded ischemic event rather than from the date of randomization, and we excluded patients with a first-recorded retinal event because we are focusing on cerebral ischemia. The prognosis of patients with retinal ischemia has been reported elsewhere. ${ }^{27}$

The primary outcome of the study was the occurrence of ipsilateral stroke in the territory of the symptomatic internal carotid artery within 90 days after the first-recorded event. The risk of ipsilateral stroke was estimated from Kaplan-Meier event-free survival curves. Differences in stroke-free survival between groups were assessed for statistical significance by the logrank test. Cox proportional hazards regression modelling was used to identify patient characteristics that increased the risk of ipsilateral stroke among those with a hemispheric TIA. Differences between proportions were assessed for statistical significance using a $\chi^{2}$ test. The relation between symptom duration in hemispheric TIA and the risk of ipsilateral stroke was also examined.

\section{Results}

Of the 1449 patients randomly assigned to the medical arm of the trial, 320 had a first-recorded retinal event (TIA 252 , stroke 68) and were excluded from further analyses. Of the remaining 1129 patients, 603 (53.4\%) had a hemispheric TIA and $526(46.6 \%)$ had a hemispheric stroke as the first-recorded event (Table 1). The mean age was 66.4 years (standard deviation [SD] 8.6), and vascular risk factors were common to the 2 groups. The median duration of a

Table 1: Characteristics of patients whose first-recorded event was hemispheric TIA or hemispheric stroke

\begin{tabular}{|c|c|c|c|}
\hline \multirow[b]{2}{*}{ Characteristic } & \multicolumn{2}{|c|}{$\begin{array}{l}\text { First-recorded event; } \\
\text { no. (and \%) of patients }\end{array}$} & \multirow[b]{2}{*}{$p$ value* } \\
\hline & $\begin{array}{l}\text { Hemispheric TIA } \\
\quad n=603\end{array}$ & $\begin{array}{l}\text { Hemispheric stroke } \\
\qquad n=526\end{array}$ & \\
\hline Age $\geq 75$ yr† & $116(19.2)$ & $91(17.3)$ & 0.40 \\
\hline Male sex & $411(68.2)$ & $368(70.0)$ & 0.51 \\
\hline Hypertension & $366(60.7)$ & $326(62.0)$ & 0.66 \\
\hline Diabetes mellitus & $128(21.2)$ & $133(25.3)$ & 0.11 \\
\hline Myocardial infarction or angina & $263(43.6)$ & $182(34.6)$ & 0.002 \\
\hline Hyperlipidemia & $226(37.5)$ & $181(34.4)$ & 0.28 \\
\hline Smoking in the past year & $259(43.0)$ & $205(39.0)$ & 0.18 \\
\hline \multicolumn{4}{|l|}{ Degree of ICA stenosis $\ddagger$} \\
\hline$<50 \%$ & $307(50.9)$ & $281(53.4)$ & \\
\hline $50 \%-69 \%$ & $157(26.0)$ & $166(31.6)$ & $0.002 \S$ \\
\hline $70 \%-99 \%$ & $139(23.1)$ & $79(15.0)$ & \\
\hline Irregular or ulcerated ICA plaque & $334(55.4)$ & $250(47.5)$ & 0.008 \\
\hline Infarct on brain imaging $\ddagger$ & $229(38.0)$ & $327(62.2)$ & $<0.001$ \\
\hline Intracranial disease of major arterył & $196(32.5)$ & $169(32.1)$ & 0.89 \\
\hline Duration of symptoms $\geq 10 \mathrm{~min}$ & $380(63.0)$ & - & - \\
\hline
\end{tabular}


hemispheric TIA was 15 minutes (interquartile range 5-60 minutes; for $72.1 \%$ the duration was less than 1 hour, and for $7.6 \%$ it was $\geq 6$ hours).

A total of 133 patients had an ipsilateral stroke within 90 days after the first-recorded event. The 90 -day risk of ipsilateral stroke was higher among patients who had had a hemispheric TIA than among those who had had a hemispheric stroke $(20.1 \%, 95 \%$ confidence interval [CI] $17.0 \%-23.2 \%$ v. $2.3 \%, 95 \%$ CI $1.0 \%-3.6 \%$; logrank test $p<0.001$ ) (Fig. 1). About one-quarter of the 90 -day stroke risk (i.e., $5.5 \%$ of $20.1 \%$ ) accrued within 48 hours after the hemispheric TIA. The event-free survival curves became parallel at about 60 days. There were no hemorrhagic events.

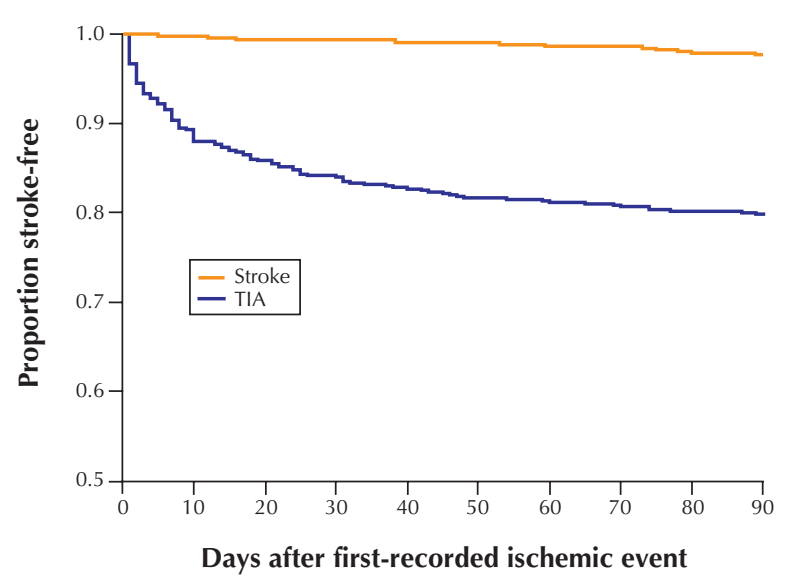

Fig. 1: Kaplan-Meier ipsilateral stroke-free survival curves from date of first-recorded hemispheric transient ischemic attack (TIA) or hemispheric stroke.
Although in most cases the stroke was large-artery in origin, more patients in the hemispheric TIA group than in the hemispheric stroke group had a lacunar stroke $(37.2 \%$ v. $8.3 \% ; \chi^{2}$ test $\left.p=0.043\right)$. The occurrence of cardioembolic stroke was low $(0.8 \%$ and $0.0 \%$ respectively).

When the hemispheric TIA patients were stratified by degree of stenosis, the event-free survival curves for ipsilateral stroke were virtually indistinguishable (logrank test $p=$ 0.93 , Fig. 2). The early hazard of ipsilateral stroke was not increased by severe $(70 \%-99 \%)$ internal carotid artery stenosis (adjusted hazard ratio $1.1,95 \%$ CI $0.7-1.7$, Table 2). Except for infarct visible on brain imaging (adjusted hazard ratio $2.1,95 \%$ CI 1.5-3.0) and the presence of intracranial major-artery disease (adjusted hazard ratio 1.9,

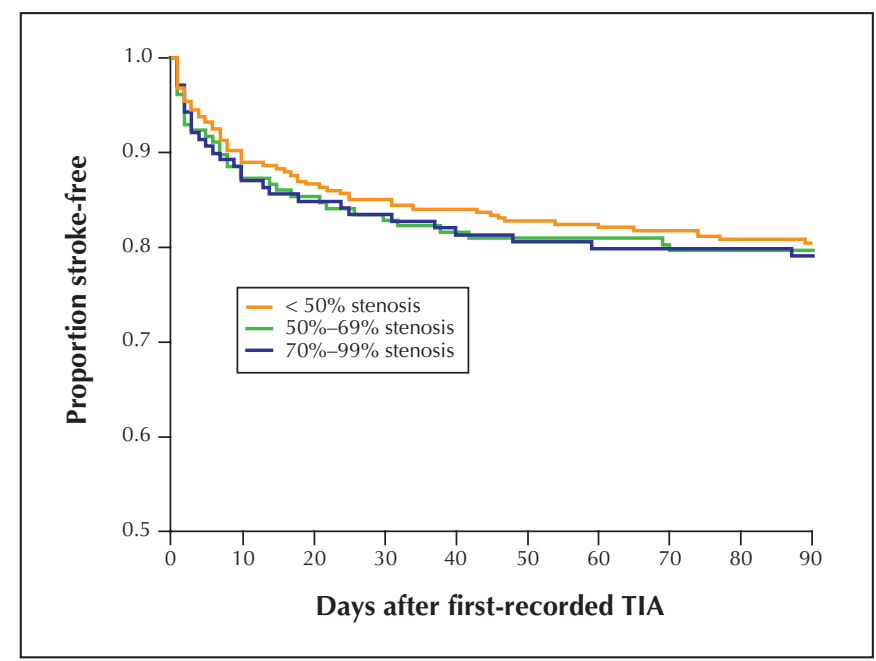

Fig. 2: Kaplan-Meier ipsilateral stroke-free survival curves from date of first-recorded hemispheric TIA by degree of internal carotid artery stenosis.

Table 2: Effect of various factors on early risk of stroke among patients with a previous hemispheric TIA

\begin{tabular}{|c|c|c|c|c|}
\hline \multirow[b]{2}{*}{ Factor } & \multicolumn{2}{|c|}{$\begin{array}{l}\text { No. of strokes/no. of patients } \\
\text { in category (and \%) }\end{array}$} & \multicolumn{2}{|c|}{ Hazard ratio* (and 95\% Cl) } \\
\hline & Factor present & Factor absent & Crude & Adjusted \\
\hline Age $\geq 75 \mathrm{yr}$ & 24/116 (20.7) & 97/487 (19.9) & $1.0(0.7-1.6)$ & $1.1 \quad(0.7-1.8)$ \\
\hline Male sex & $89 / 411(21.6)$ & 32/192 (16.7) & $1.3(0.9-1.9)$ & $1.3 \quad(0.9-2.0)$ \\
\hline Hypertension & $71 / 366(19.4)$ & $50 / 237(21.1)$ & $0.9 \quad(0.6-1.3)$ & $0.9(0.6-1.2)$ \\
\hline Diabetes mellitus & $32 / 128(25.0)$ & $89 / 475(18.7)$ & $1.4(0.9-2.1)$ & $1.3(0.8-1.9)$ \\
\hline Myocardial infarction or angina & $58 / 263(22.0)$ & $63 / 340(18.5)$ & $1.2(0.8-1.7)$ & $1.1 \quad(0.8-1.6)$ \\
\hline Hyperlipidemia & $48 / 226(21.2)$ & $73 / 377(19.4)$ & $1.1(0.8-1.6)$ & $1.2(0.8-1.7)$ \\
\hline Smoking in the past year & $54 / 259(20.8)$ & $67 / 344(19.5)$ & $1.1 \quad(0.7-1.5)$ & $1.1(0.8-1.7)$ \\
\hline ICA stenosis 70\%-99\%† & 29/139 (20.9) & 92/464 (19.8) & $1.1 \quad(0.7-1.6)$ & $1.1 \quad(0.7-1.7)$ \\
\hline Irregular or ulcerated ICA plaque† & 66/334 (19.8) & $55 / 269(20.4)$ & $1.0(0.7-1.4)$ & $0.9(0.6-1.2)$ \\
\hline Infarct on brain imaging $\dagger$ & $67 / 229(29.3)$ & $54 / 374(14.4)$ & $2.2(1.5-3.1) \neq$ & $2.1 \quad(1.5-3.0) \neq$ \\
\hline Intracranial disease of major artery disease $\dagger$ & $56 / 196(28.6)$ & $65 / 407(16.0)$ & $1.9(1.3-2.8) \neq$ & 1.9 (1.3-2.7)† \\
\hline Duration of symptoms $\geq 10 \mathrm{~min}$ & $81 / 380(21.3)$ & 40/223 (17.9) & $1.2(0.8-1.8)$ & $1.2(0.8-1.8)$ \\
\hline
\end{tabular}

Note: $\mathrm{Cl}=$ confidence interval, ICA = internal carotid artery, $\mathrm{TIA}=$ transient ischemic attack.

*Hazard ratios were calculated by means of Cox regression analysis. They were adjusted for all other factors listed in this table. †Ipsilateral to the territory of the first-recorded hemispheric TIA.

$\neq p<0.001$. 
95\% CI 1.3-2.7), hazard ratios associated with other characteristics were close to 1 . The 90-day risk of ipsilateral stroke increased with symptom duration in patients with hemispheric TIA, but was not statistically significant (logrank test $p=0.58$, test for trend $p=0.34$, Fig. 3 ).

\section{Interpretation}

This study demonstrated that the risk of ipsilateral stroke among patients with symptomatic internal carotid artery disease was $5.5 \%$ within the first 2 days after a firstrecorded hemispheric TIA and $20.1 \%$ in the first 90 days. The 90-day risk was not affected by the degree of stenosis. The risk was lower among patients with a first-recorded hemispheric stroke than among patients with a firstrecorded hemispheric TIA. In about two-thirds of the patients who had an ipsilateral stroke, it was large-artery in origin, which implicated the newly symptomatic internal carotid artery. The cause was cardioembolic in few of the cases of stroke, because patients harbouring a probable cardiogenic stroke were excluded from entry into the trial.

A previous study ${ }^{5}$ reported that older age, diabetes mellitus and duration of symptoms were predictors of early stroke in patients diagnosed with a TIA. In our study, increased risk of stroke was significantly associated only with infarct visible on brain imaging and the presence of intracranial major-artery disease. Risk of stroke did increase with longer duration of symptoms, but the result did not reach statistical significance. The difference in risk factors is primarily due to the different case-mix of patients in these studies; our study included only patients with symptomatic internal carotid artery disease.

The large randomized trials ${ }^{23,28}$ demonstrating the efficacy of carotid endarterectomy for symptomatic internal carotid artery stenosis reported a positive relation between

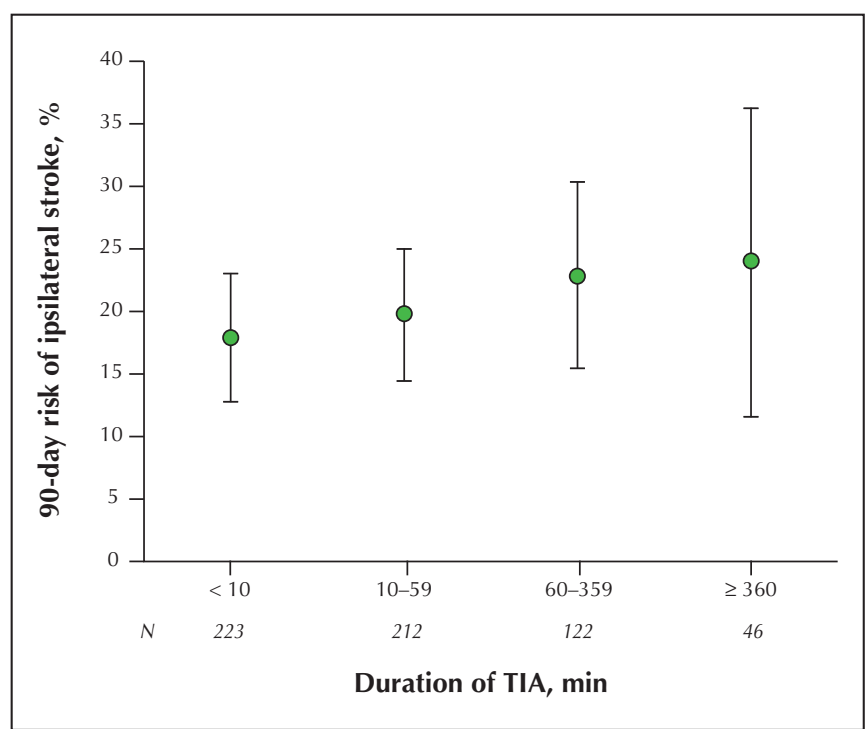

Fig. 3: The 90-day risk of ipsilateral stroke by duration of firstrecorded hemispheric TIA. Error bars $=95 \%$ confidence intervals. degree of stenosis and long-term risk of stroke. In our study, the degree of stenosis did not affect the early risk of stroke. The high early risk of stroke might, therefore, be the result of a ruptured plaque in a stenosed carotid artery. However, if this were the only mechanism for stroke occurrence, then the risk of stroke would have been the same for patients presenting with a completed stroke as for those with a hemispheric TIA. The striking disparity between the 2 groups observed in our study suggests other mechanisms that are unclear at this time. New imaging techniques may shed some light by making accurate visualization of the carotid plaque possible and allow characterization of the effect of plaque instability on stroke risk. . $^{29,30}$

Almost $75 \%$ of the patients with a hemispheric TIA had symptoms that lasted less than 1 hour. The number of patients who had hemispheric TIA symptoms persisting beyond 1 hour diminished with time, which is congruent with the proposed new definition for TIA, namely the longer that symptoms persist, the less likely they are to resolve. ${ }^{31}$

Because TIA is a historical clinical diagnosis, ${ }^{32}$ the results of this trial are limited by the ability of patients to recall their symptoms. This difficulty is shared by all studies of TIA. However, because the stroke neurologists participating in this trial specifically collected detailed information about ischemic events occurring 180 days before randomization, every attempt was made to minimize the effects of poor recall.

In conclusion, a hemispheric TIA in the presence of internal carotid artery disease confers a high risk of stroke in the immediate aftermath of the artery becoming symptomatic. Concerted efforts to conduct randomized trials focusing solely on the acute phase are now required to determine optimal intervention strategies for stroke prevention.

\section{This article has been peer reviewed.}

From the Departments of Community Health Sciences (Eliasziw, Hill), Clinical Neurosciences (Eliasziw, Kennedy, Hill, Buchan) and Medicine (Hill), University of Calgary, Calgary, Alta.; and the John P. Robarts Research Institute, London, Ont. (Barnett)

Competing interests: None declared.

Contributors: Michael Eliasziw designed the study, drafted the manuscript and performed the statistical analyses. James Kennedy contributed to the design of the study, conducted the literature review and contributed to the writing of the manuscript. Michael Hill contributed to the statistical analyses, the mode of presentation of the data and the writing of the manuscript. Alastair Buchan contributed to the writing of the manuscript, particularly its organization. Henry Barnett, principal investigator in the NASCET, contributed to the design and writing of the manuscript. All of the authors approved the final version of the manuscript.

Acknowledgements: This study was supported by grant R01-NS-24456 from the National Institute of Neurological Disorders and Stroke. The authors acknowledge the support of all participants in the NASCET. Michael Eliasziw was supported by the National Institute of Neurological Disorders and Stroke, the Natural Sciences and Engineering Research Council of Canada and the Alberta Heritage Foundation for Medical Research. James Kennedy holds a salary award from the Canadian Stroke Network, the Heart and Stroke Foundation of Canada, the Canadian Institutes of Health Research and AstraZeneca. Michael Hill was supported by the Heart and Stroke Foundation Alberta/Northwest Territories and the Canadian Institutes for Health Research. Alastair Buchan was supported by the Heart and Stroke Foundation Alberta/Northwest Territories, the Alberta Heritage Foundation for Medical Research and the Canadian Institutes for Health Research. 


\section{References}

1. TIA/mini strokes: public knowledge and experience (Roper Starch Worldwide survey). Englewood (CO): National Stroke Association; 2000.

2. Graves RJ. Clinical lectures on the practice of medicine. London: New Sydenham Society; 1884.

3. Chiari H. Ueber das Verhalten des Teilungswinkels der Carotis communis bei der Endarteriitis chronic deformans. Verb Dtsch Ges Pathol 1905:9:326-30.

4. Fisher CM. Occlusion of the internal carotid arteries. Arch Neurol Psychiatry 1951;65:346-77.

5. Johnston SC, Gress DR, Browner WS, Sidney S. Short-term prognosis after emergency department diagnosis of TIA. 7AMA 2000;284(22):2901-6.

6. Whisnant JP, Matsumoto N, Elveback LR. Transient cerebral ischemic attacks in a community. Mayo Clin Proc 1973;48(3):194-8.

7. Whisnant JP, Wiebers DO, O'Fallon WM, Sicks JD, Frye RL. Effect of time since onset of risk factors on the occurrence of ischemic stroke. Neurology 2002;58(5):787-94

8. Dennis MS, Bamford JM, Sandercock PA, Warlow CP. A comparison of risk factors and prognosis for transient ischemic attacks and minor ischemic strokes. Stroke 1989;20(11):1494-9.

9. Bousser MG, Eschwege E, Haguenau M, Lefaucconnier JM, Thibult N, Touboul D, et al. "AICLA" controlled trial of aspirin and dipyridamole in the secondary prevention of athero-thrombotic cerebral ischaemia. Stroke 1983;14(1):5-14.

10. Canadian Cooperative Study Group. A randomized trial of aspirin and sulfinpyrazone in threatened stroke. N Engl 7 Med 1978;299(2):53-9.

11. Fields WS, Lemak NA, Frankowski RF, Hardy RJ. Controlled trial of aspirin in cerebral ischemia. Stroke 1977;8(3):301-14.

12. Sorensen PS, Pedersen H, Marquardsen J, Petersson H, Heltberg A, Simonsen $\mathrm{N}$, et al. Acetylsalicylic acid in the prevention of stroke among patients with reversible cerebral ischemic attacks: a Danish cooperative study. Stroke $1983 ; 14(1): 15-22$

13. SALT Collaborative group. Swedish Aspirin Low-Dose Trial (SALT) of $75 \mathrm{mg}$ aspirin as secondary prophylaxis after cerebrovascular ischaemic events. Lancet 1991;338(8779):1345-9.

14. Farrell B, Godwin J, Richards S, Warlow C. The United Kingdom transient ischaemic attack (UK-TIA) aspirin trial: final results. 7 Neurol Neurosurg Psychiatry 1991;54(12):1044-54.

15. Dutch TIA Trial Study Group. A comparison of two doses of aspirin (30 mg vs. $283 \mathrm{mg}$ a day) in patients after a transient ischemic attack or minor ischemic stroke. N Engl 7 Med 1991;325(18):1261-6.

16. Hass WK, Easton JD, Adams HP Jr., Pryse-Phillips W, Molony BA, Anderson $\mathrm{S}$, et al. A randomized trial comparing ticlopidine hydrochloride with aspirin for the prevention of stroke in high-risk patients. $N$ Engl 7 Med 1989; 321(8):501-7.

17. Diener H, Cunha L, Forbes C, Sivenius J, Smets P, Lowenthal A. European Stroke Prevention Study 2. Dipyridamole and acetylsalicylic acid in the secondary prevention of stroke. 7 Neurol Sci 1996;143(1-2):1-13.

18. American-Canadian Co-Operative Study Group. Persantine aspirin trial in cerebral ischaemia. Part II: Endpoint results. Stroke 1985;16(3):406-15.

19. Barnett HJM. Transient cerebral ischemia. Ann R Coll Physic Surg Can 1974; 7:154-73.

20. Pessin MS, Duncan GW, Mohr JP, Poskanzer DC. Clinical and angiographic features of carotid transient ischemic attacks. N Engl 7 Med 1977;296(7):358-62.

21. Mohr JP, Gautier JC, Pessin MS. Internal carotid artery disease. In: Barnett HJM, Mohr JP, Stein BM, Yatsu FM, editors. Stroke: pathophysiology, diagnosis, and management. New York: Churchill-Livingstone; 1998. p. 355-400.

22. NASCET Steering Committee. North American Symptomatic Carotid Endarterectomy Trial: methods, patients, characteristics and progress. Stroke 1991;22(6):711-20

23. Barnett HJM, Taylor DW, Eliasziw M, Fox AJ, Ferguson GG, Haynes RB, et al. Benefit of carotid endarterectomy in patients with symptomatic moderate or severe stenosis. North American Symptomatic Carotid Endarterectomy Trial Collaborators N Engl f Med 1998;339(20):1415-25.

24. Fox AJ. How to measure carotid stenosis. Radiology 1993;186(2):316-8.

25. Inzitari D, Eliasziw M, Sharpe BL, Fox AJ, Barnett HJ. Risk factors and outcome of patients with carotid artery stenosis presenting with lacunar stroke. Neurology 2000;54(3):660-6.

26. Barnett HJM, Gunton RW, Eliasziw M, Fleming L, Sharpe B, Gates P, et al. Causes and severity of ischemic stroke in patients with internal carotid artery stenosis. FAMA 2000;283(11):1429-36.

27. Benavente O, Eliasziw M, Streifler JY, Fox AJ, Barnett HJ, Meldrum H, et al. Prognosis after transient monocular blindness associated with carotid-artery stenosis. N Engl 7 Med 2001;345(15):1084-90.

28. Randomised trial of endarterectomy for recently symptomatic carotid stenosis: final results of the MRC European Carotid Surgery Trial (ECST). Lancet 1998;351(9113):1379-87.
29. Yuan C, Zhang SX, Polissar NL, Echelard D, Ortiz G, Davis JW, et al. Identification of fibrous cap rupture with magnetic resonance imaging is highly associated with recent transient ischemic attack or stroke. Circulation 2002;105(2):181-5.

30. Spence JD, Eliasziw M, DiCicco M, Hackam DG, Galil R, Lohmann T. Carotid plaque area: A tool for targeting and evaluating vascular preventive therapy. Stroke 2002;33(12):2916-22.

31. Albers GW, Caplan LR, Easton JD, Fayad PB, Mohr JP, Saver JL, et al Transient ischemic attack - proposal for a new definition. $N$ Engl $7 \mathrm{Med}$ 2002;347(21):1713-6.

32. Levy DE. How transient are transient ischemic attacks? Neurology 1988;38 (5):674-7.

Correspondence to: Dr. Alastair M. Buchan, Department of Clinical Neurosciences, University of Calgary, Foothills Hospital, 1403 29th St. NW, Calgary AB T2N 2T9; fax 403 944-1602; abuchan@ucalgary.ca 